\title{
EL HOSPITAL NOS DIVIDIÓ
}

\author{
IX Premio Vida y Salud de Narrativa (2008) \\ Modalidad profesional/estudiantes de enfermería
}

Ana Fernández Conde

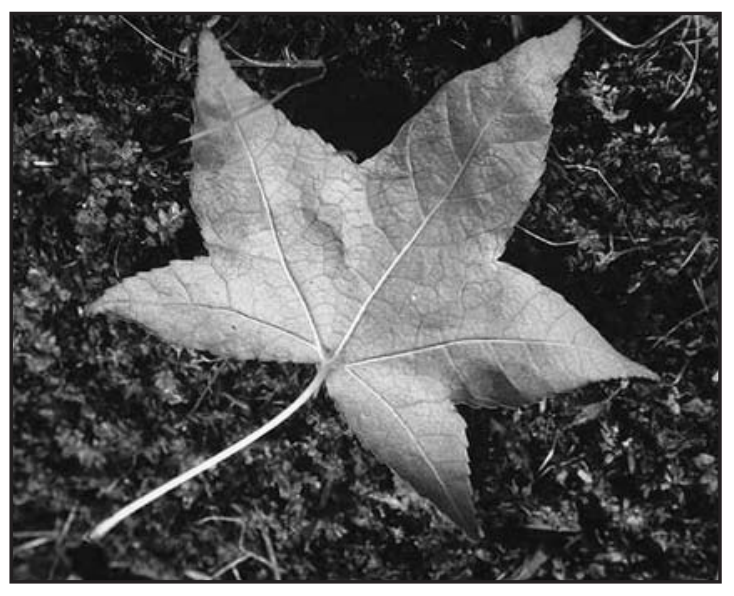

Era la primavera del año 1944. Yo acababa de cumplir 16 años y vivía la tensión del vecindario entre la sorpresa y la indiferencia. El nuevo hospital que estaban construyendo en pleno centro de nuestro pequeño pueblo tenía a todos crispados e indignados. Yo no acababa de entender el porqué ya que desconocía por completo la gravedad de aquella enfermedad de la que hablaban continuamente: la tuberculosis; pero sí me sentía afectada por la situación ya que el malestar general había conseguido que las familias se encerraran en sus casas (no sé muy bien si para preparar sus "armas de guerra" o para ir acostumbrándose a la vida que les esperaba) y cada vez era más difícil salir a pasear con las amigas o ir a alguna fiesta a bailar.

Durante los meses siguientes un enorme edificio de piedra se fue alzando en medio de las casas. Ese edificio sería un hospital que albergaría tuberculosos. El pueblo tenía miedo, pánico a dicha enfermedad. Estoy casi segura de que ninguno de los vecinos sabía exactamente en qué consistía ni cuál era el grado de riesgo que íbamos a correr, pero todos tenían claro que de eso se moría la gente, que era contagioso y que no querían ese tipo de enfermos tan cerca de sus casas, de sus hijos... A mí aquel hospital se me antojaba un enorme monstruo que se alzaba imponente y avasallador en medio de las pequeñas y aterrorizadas casas del pueblo. A medida que su construcción avanzaba, yo tenía la sensación de que iba cobrando vida, alimentándose de la ira y el pánico de un pueblo que lo rechazaba y enfureciéndose con el odio con que lo miraban los vecinos al pasar. La quietud y sobriedad de sus largas paredes de piedra se convertían, en mi adolescente cabeza, en enormes brazos que daban bruscos zarpazos para intentar amedrentarme e inmovilizarme.

"No hace falta conocer el peligro para tener miedo, de hecho, los peligros desconocidos son los que inspiran más temor”. (Alejandro Dumas)

Las limitadas protestas que se podían hacer dentro de los márgenes de la dictadura fueron inútiles. El mismísimo General Francisco Franco vino a inaugurarlo en Octubre del mismo año. Aunque los más cercanos al régimen quisieron ver en esto una posibilidad más de solicitar que fuera otro el fin de tan majestuoso edificio la mayoría pensaron que el tener a tantos falangistas cerca durante tanto tiempo (para la preparación de la venida del dictador) no haría más que sumar problemas a la ya complicada situación.

Así iban pasando los días. Mi ignorancia y mi juventud me permitían mantenerme bastante distanciada de estas preocupaciones hasta que un día mi madre me llamó con una seriedad especial y me dijo que quería hablar conmigo.

- Luisa, acompáñame, tenemos que hablar. -No fue sólo el tono de voz lo que me preocupó, también el ver que se dirigía hacia su habitación. Mi madre nunca nos llevaba a su habitación. Era su refugio.

- Verás, hija, las cosas no van bien. Tu padre trabaja de sol a sol pero no es suficiente; casi no tenemos para comer, no compramos ropa y los zapatos de tus hermanos están rotos. Sois tres bocas a alimentar sin contar la de tu padre 
y la mía, y... otra más que viene en camino... Tú eres la mayor de tus hermanos y necesito pedirte que nos ayudes. Tu padre ha hablado con su jefe y le ha dicho... que... seguramente te darán trabajo en el hospital.

- ¿En el hospital?, pero mamá!, la gente dice que si trabajas en el hospital te puedes morir, vosotros mismos luchasteis para que no se construyera! Además yo no sé nada de enfermos..., no se ni siquiera qué es eso de la tuberculosis, mamá ¿qué voy a hacer allí?, yo no soy enfermera.

- No hace falta, hija. En el hospital se pueden hacer muchas cosas, los enfermos necesitan que alguien les cocine, les lave la ropa, les limpie las habitaciones... Y no tengas miedo hija, no es cierto lo que dicen, no te vas a morir por trabajar ahí. ¿Acaso no están trabajando desde que abrió Raúl y Gerardo?, y Teresa y Paco... ¿Y tu ves que alguno haya enfermado o le haya pasado algo? No. No te preocupes hija.

Los ojos llenos de lágrimas de mi madre me hicieron entender que en realidad no estaba tan segura de que no me pasaría nada, pero la necesidad de conseguir lo más básico para su familia ahogaba el posible temor por mi salud.

- Yo misma iría si pudiera hija, pero embarazada y con dos niños tan pequeños... Necesito que seas tu... ¿lo entiendes verdad?- ¡Era tan evidente el tono de desesperación de mi madre! ¿Qué otra cosa podría llevar a una madre a enviar a su hija a un "infierno" en el que encontraría con seguridad el desprecio de su pueblo, con alta probabilidad la enfermedad y con cierta posibilidad la muerte?

- Claro mamá - sonreí como si estuviera feliz de ayudar a mi familia. Pero en realidad me veía a mí misma abocada a un precipicio, muerta de miedo por lo que pudiera pasar y totalmente angustiada de ver a mi madre en tal extremo de desesperación.

\section{“ ¿Miedo a la muerte? Uno debe de temerle a la vida, no a la muerte”. (Marlene Dietrich)}

Tres días después fui a entrevistarme con el Administrador del hospital. Era un hombre corpulento y serio, me impresionó tanto que pensé que era la persona ideal para dirigir aquel sitio ya que ambos me daban exactamente el mismo miedo. Me hizo algunas preguntas que nada tenían que ver con los enfermos o con la enfermedad y a continuación me dijo: - vete a la primera planta y pregunta por Sor Aurora, dile que vas de mi parte y que te pongan la tuberculina; mañana vuelve a que te la lea, si prendió empezarás a trabajar... quizás en la lavandería... hace falta una persona allí.- Así de sencillo. Por aquel entonces los conocimientos sobre la tuberculosis no eran muchos ni muy precisos; querían a gente con Mantoux positivo, creían que así eran resistentes a la enfermedad. Casi todos los del pueblo lo teníamos ya que los enfermos paseaban al lado de nuestras casas, iban a nuestros bares, visitaban nuestra Iglesia... Intentábamos separarnos de ellos pero en realidad lo único que conseguíamos era aislarnos, mientras ellos, que no tenían nada que perder, ajenos a nuestro desprecio, hacían una vida normal usufructuando nuestro pueblo.

\section{"Un hombre aislado se siente débil, y lo es". (Concepción Arenal)}

Y de esta forma empecé a trabajar en la lavandería, 24h al día 7 días a la semana. Vivíamos allí; nos daban la comida, teníamos donde dormir y además llevábamos dinero a casa... era difícil resistirse en una época de tanta miseria. A pesar de lo duro que era vivir allí. Lo peor: el frío. Todas las puertas y ventanas del hospital estaban siempre abiertas de par en par. Se buscaba la cura del aire. Por ello también había hamacas, colocadas a lo largo de los más de 300 metros de balconadas que tenía el edificio, en las que los enfermos pasaban tumbados buena parte del día tanto en verano como en invierno. Trabajar en lavandería o en cocina era casi un lujo porque allí teníamos el calor de las planchas o de los fogones respectivamente. ¡Cuánto frío pasamos! Muchos enfermos bromeaban diciendo que si no se morían de la tuberculosis se morirían del frío.

Eran enfermos que estaban ingresados en el mejor de los casos meses y en muchas ocasiones años. Era mucho tiempo por lo que los médicos, cuando no estaban en fase contagiosa, les daban permiso para salir del hospital. Paseaban por el pueblo, visitaban los bares y tabernas de la zona, 
iban a la Iglesia... Pero al anochecer, para la hora de la cena, todos estábamos allí de nuevo, trabajadores y enfermos, comentando con más o menos ilusión y esperanza, cómo había transcurrido un día más de nuestras vidas. Así las cosas el pueblo se dividió todavía más: por un lado los que seguían inamovibles en su lucha contra el hospital y por otro los que se habían dejado doblegar por la necesidad y habían sucumbido al encanto de una buena comida, una habitación y una pequeña cantidad de dinero asegurada.

Fueron pasando los días, los meses, los años... Poco a poco nos fuimos olvidando de la enfermedad como tal y, dado que pasábamos en el hospital todo nuestro tiempo y que el pueblo nos despreciaba y no quería relacionarse con nosotros dejamos de ser empleados y enfermos para pasar a ser todos, sin distinción, una gran familia.

El trabajo era duro. Las monjas eran las que mandaban. La mayoría de estas monjas eran enfermeras. Las respetábamos con cierto temor porque no dudaban en llamarnos la atención si no hacíamos correctamente nuestro trabajo pero también las admirábamos porque no era difícil ver que luchaban contra aquella durísima enfermedad sin los suficientes medios ni conocimientos. Anteponían el bienestar del enfermo a su propia vida burlando el contagio con viejas mascarillas de tela que se usaban una y otra vez sin ningún tipo de desinfección, limpiaban personalmente esputos, vómitos o cualquier otro resto orgánico sin guantes y "esterilizaban" los colchones de los que fallecían con el vapor de una cocina de carbón. Racionaban la comida para que llegara para todos. Zurcían las sábanas, pijamas y camisones porque pasaban años $\sin$ que repusieran la ropa. Colaboraban con el médico en la realización de técnicas que en aquella época se consideraban totalmente innovadoras y que hoy nos resultarían casi "salvajes". Quizás jerárquicamente sobre ellas estuvieran los médicos y el administrador pero eso no se notaba en el trabajo diario. Ellas eran las que mandaban, las que organizaban el trabajo, las que controlaban las comidas, las que cuidaban los enfermos, las que daban los permisos para salir a pasear (tanto a personal como a enfermos), y las que nos llamaban la atención si algo estaba mal hecho. Sin ellas, sin esas monjas enfermeras el hospital no hubiera sobrevivido. No sé si el ser monjas les daba una mayor fuerza moral pero si sé que poseían una entrega, dedicación y coraje que es fácil de ver en las enfermeras vocacionales pero difícil de encontrar en cualquier otra profesión.

No creo que sea difícil entender que pasando tanto tiempo juntos y siendo como éramos la mayoría gente joven, en muchas ocasiones surgiera el amor. También en mi caso. No fue una historia especialmente llamativa como cuando Sor Jacinta se enamoró del paciente de la 207, colgó los hábitos y se casaron. Yo me enamoré del pinche de cocina. Tuvimos un par de años de noviazgo y al poco de cumplir yo los 19 nos casamos. Ramón tenía 20. Ser matrimonio y vivir en el hospital era duro. Por supuesto no teníamos una habitación para nosotros solos sino que seguíamos cada uno en la que teníamos antes, en ocasiones incluso compartida con dos o tres compañeros más. Aún así nos las ingeniábamos para estar juntos y para vivir nuestros momentos especiales, éramos jóvenes y estábamos recién casados... En poco menos de un año me quedé embarazada de mi primer hijo. Fue entonces cuando empezamos a darnos cuenta de nuevo de que estábamos trabajando en un hospital de tuberculosos y de que corríamos peligro; por supuesto habíamos perdido hacía mucho tiempo el miedo a enfermar nosotros, pero no estábamos dispuestos a exponer a nuestro hijo a tal posibilidad. Afortunadamente, a los tres meses de embarazo, a Ramón lo ascendieron a jefe de cocina y eso nos dio el empuje que necesitábamos para tomar la decisión que llevábamos ya un tiempo intentando tomar: yo dejé de trabajar en el hospital.

- No te preocupes, Luisa -me decía mi maridoahora yo voy a ganar algo más y nos arreglaremos. Tú puedes vivir en casa de tus padres y apenas gastarás nada hasta que nazca el niño, para entonces ya tendremos algo ahorrado y tiraremos para adelante.

- ¿Estás seguro, Ramón? Tu sueldo no es muy grande y aquí no gastaría en comida para mí...

- Claro que estoy seguro. Lo primero es nuestro hijo. Nos arreglaremos, ya lo verás.

Yo sabía que las cosas no iban a ser tan fáciles como Ramón me las pintaba y no me equivoqué: 


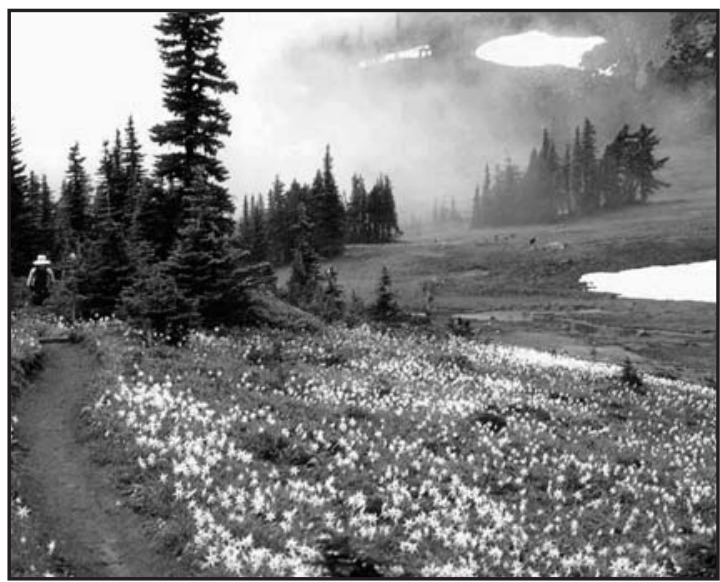

fueron muy duras. Pero no por las dificultades económicas como yo pensaba, sino por algo mucho peor: el rechazo de todos mis vecinos; me trataban como a una apestada, no podía casi salir de casa porque en el mejor de los casos me miraban mal y en el peor me insultaban directamente. Sólo podía hablar con mis padres y hermanos que después de varios años habían conseguido superar ese desprecio y hacían una vida relativamente normal, al margen de todo comentario u ofensa.

"El que desprecia demasiado se hace digno de su propio desprecio”. (Henri Frédéric Amiel)

Mi embarazo transcurrió con normalidad. Como Ramón predijo conseguimos ahorrar algo de dinero, no sólo por su sueldo sino más bien por el ingenio de Ramón. No es que él fuera especialmente pícaro pero en aquella época la necesidad y el hambre hacían avispado al más inocente de los hombres. Así, Ramón escondía fruta dentro de su chaqueta cuando Sor Aurora le pedía que ayudara a descargar el camión que la suministraba, cobraba una propinilla de los médicos cuando éstos le firmaban una receta a su nombre de aquella medicina tan cara para la tuberculosis (que Ramón por su puesto no necesitaba), los enfermos a los que no le permitían salir del hospital, porque estaban en fase contagiosa, le daban algo para que les comprara vino o tabaco en la taberna,... Y Ramón aprovechaba las noches en las que todo estaba tranquilo para dejar una almohada debajo de las sábanas y venir a traerme a casa todo lo que había consegui- do; bueno, a eso y también a verme, al fin y al cabo nos acabábamos de casar.

Nació nuestro primer hijo y fue entonces cuando fuimos realmente conscientes de la realidad de nuestras vidas. Lo bautizamos en el hospital y en la única foto que conservo de aquel día se ve claramente la situación en la que vivíamos. Estamos a las puertas del hospital mi marido y yo con el niño en brazos junto a nuestra familia: los empleados del hospital y los enfermos. Nadie más.

"No es la carne y la sangre, sino el corazón, lo que nos hace padres e hijos". (Jonhann Christoph Friedrich von Schiller)

La familia no es únicamente la que unen los lazos de sangre. Nosotros comprobamos cómo la familia es aquella que frente a la adversidad y al aislamiento de los que los rodean se une y se hace fuerte.

Todos juntos, personal del hospital y enfermos, vivimos todo tipo de sentimientos: festejábamos la Navidad, el Carnaval, la matanza, los magostos,... con ilusión y alegría. Celebrábamos las bodas, bautizos, comuniones con emoción y entrega. Llorábamos a los fallecidos con verdadero sentimiento y los enterrábamos cuando ningún familiar los reclamaba (cosa que ocurría frecuentemente, sobre todo entre los enfermos). Éramos capaces de reír y llorar, de cantar o bailar y de enfadarnos, de trabajar intensamente y de escaquearnos del trabajo, de escuchar y de contar nuestras penas, de alegrarnos y de entristecernos. En resumen, éramos capaces de vivir. De vivir intensamente y al margen de un pueblo que nos rodeaba pero que nos había rechazado; que estaba a nuestro lado pero que no quería tocarnos.

\section{"Los lazos de la amistad son más estrechos que los de la sangre y la familia”.}

(Giovanni Boccaccio)

Siempre había alguna situación que nos recordaba quienes éramos. Nuestros hijos jugaban en los pasillos del hospital pero no tenían amigos fuera de él; nosotros tampoco. Eso nos dolía profundamente, a pesar de que lo llevábamos con mucha dignidad. 
Vivíamos en un mundo que hoy probablemente definirían como "virtual", es decir, en un mundo imaginario, tremendamente real, que nos resultaba más que suficiente, pero que en determinadas ocasiones nos propinaba una fuerte "bofetada" y nos traía de golpe a la realidad. Como cuando nuestros hijos iban al colegio y los demás niños no querían jugar con ellos, o cuando no nos permitían entrar en el centro social, o cuando se negaban a venir a nuestras casas, o cuando prohibían a los niños pasar caminando por los alrededores del hospital,...

Ha pasado mucho tiempo. El hospital ya tiene más de 50 años. Lo único que le queda en común con el original son sus majestuosas paredes de piedra. Todo ha cambiado. Hoy está considerado el hospital más bonito de los tres que posee la ciudad ya que está rodeado de árboles, flores, pájaros, ardillas,... Por las grandes balconadas por las que un día paseaban tuberculosos hoy pasean ancianos con patología respiratoria o cardiovascular. Ya nadie tiene miedo. Ya nadie se fija en que en el centro del pueblo hay un enorme edificio de piedra que alberga enfermos. La gente joven ni siquiera sabe que el pueblo en el que viven un día estuvo dividido con el temor a un lado y la miseria al otro. La gente mayor ha querido olvidarlo, bien porque, por fin, ya no sienten desprecio en las miradas de sus vecinos o bien porque tienen remordimientos por haber despreciado a aquellos con los que convivían.
"Perdonar supone siempre un poco de olvido, un poco de desprecio y un poco de comodidad"

\section{(Jacinto Benavente).}

Yo, a punto de cumplir 80 años, me siento feliz y agradecida por haber conocido a mi marido, por haber tenido tres maravillosos hijos con él y porque ninguno de nosotros enfermó. Otros no tuvieron tanta suerte, enfermaron e incluso algunos llegaron a morir. Me siento también agradecida de haber "vivido" y "convivido" en el hospital. Allí aprendí de las enfermeras la dedicación, la entrega y el coraje; de los enfermos la ilusión, la esperanza y el espíritu de lucha y de mis compañeros la solidaridad y el respeto. ¡Que intensa y cálida llegó a ser mi vida en el interior de aquel frío hospital!

Ahora tengo el corazón partido en dos mitades. Una está llena de amargura y tristeza por haber estado encerrada y aislada del mundo en el que nací, y al que se suponía que pertenecía, durante tantos años. La otra mitad está llena de cariño y agradecimiento a toda aquella gente que vivió en el hospital, como trabajadores o como enfermos, y que me regaló una nueva, numerosa y maravillosa familia cuando me quedé sin ella y cuando precisamente más la necesitaba.

No cambiaría ni uno de los minutos que viví dentro del hospital pero cambiaría casi todos lo que viví fuera de él desde que se construyó.

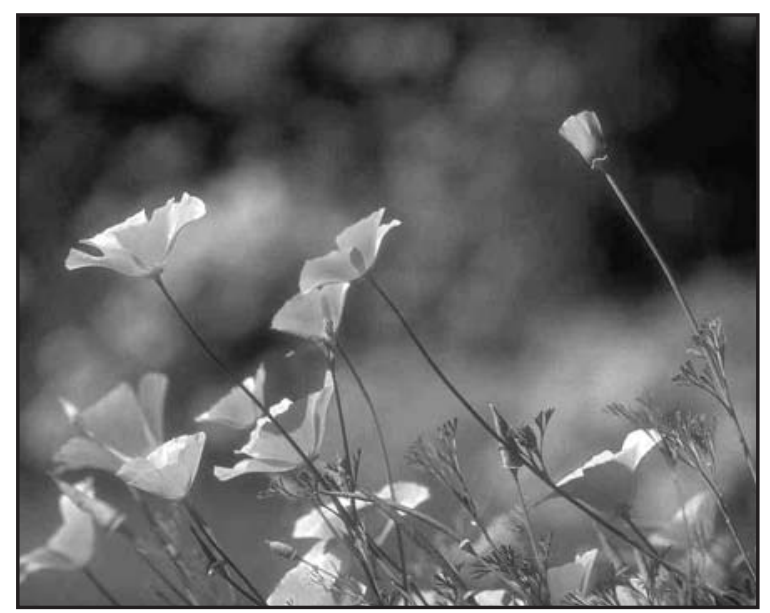

